АКОПОВ Гарник Владимирович - доктор психологических наук, профессор; заведующий кафедрой общей и социальной психологии факультета психологии Самарского государственного социальнопедагогического университета (443099, Россия, г. Самара, ул. М. Горького, 65/67; kaf.soc.ps@sgspu. ги); заслуженный деятель науки РФ

АКОПЯН Любовь Суреновна - доктор психологических наук, доцент; профессор кафедры педагогики и психологии Самарского государственного социально-педагогического университета (443099, Россия, г. Самара, ул. М. Горького, 65/67; akolubov@таil.ru)

БЕЛОУС Анна Вячеславовна - аспирант кафедры общей и социальной психологии Самарского государственного социально-педагогического уфниверситета (443099, Россия, г. Самара, ул. М. Горького, 65/67)

\title{
АССОЦИАТИВНОЕ СОЗНАНИЕ В ЦВЕТОВОЙ И ГЕОМЕТРИЧЕСКОЙ ПРОЕКЦИЯХ: СОЦИОЛОГИЧЕСКИЙ И ПСИХОЛОГИЧЕСКИЙ АСПЕКТЫ ДИАГНОСТИКИ ОТНОШЕНИЙ ЛИЧНОСТИ
}

\begin{abstract}
Аннотация. В материале рассматривается метод исследования оценок респондентами социальных явлений, предусматривающий отход от прямого вербального обозначения личного отношения человека к объекту или процессу. Наличие промежуточного знака, с которым респондент связывает свое отношение к изучаемому явлению, помогает выявить реальную подсознательную позицию опрашиваемого по отношению к явлениям, которые в его сознании имеют типологическую привязку к официальной социально одобряемой позиции. Подход помогает существенно повысить качество первичного материала, собираемого при опросе, за счет существенного снижения числа ответов, которые респонденты дают не в соответствии с имеющейся индивидуальной позицией, а привязывая их к ожиданиям анкетера, рассматривая вопросы анкеты как своеобразный тест на лояльность.

Ключевые слова: методика социологического опроса, психологическое тестирование, диагностика отношений личности, цветоассоциативные оценки, ассоциативно-геометрические оценки, объектные контексты, субъектные контексты
\end{abstract}

\footnotetext{
оциальная динамика человеческих сообществ в новом тысячелетии характеризуется существенно возросшей частотой социальных турбуленций [Акопов 2016], предположительно индуцируемых сегодня все более широкой доступностью социальных коммуникаций для каждой личности и их целенаправленной технологизацией. В этой связи можно говорить, что социология массовых явлений становится все более личностно обусловленной, т.е. психологичной, а психология - социально обусловленной. Планомерность, постоянно нарушаемая ситуативностью, социальная неопределенность с императивом личностной автономии, непрерывная коммуникативность в ущерб успокоительному созерцанию становятся нормой жизни. Соответственно этому, рецептивность как продуманная планомерность и определенность жизни, мыслей, действий и переживаний сознательной личности вытесняется ассоциативными реакциями, кратковременными эмоциональными откликами, спонтанными поступками субъектов сиюминутного осознания.

Приведенная выше совокупность факторов, определяющая специфику современной жизни, очевидно, связана с релевантными состояниями сознания личности и различных социальных групп. Проблематика сознания в современных зарубежных, отчасти отечественных работах становится мейнстримом
} 
философских и научных исследований [Петренко 2013; Акопов 2010; Акопов 2019]. Отчетливо выделяются два направления исследований: одно из них заключается в изучении взаимосвязи сознания и мозговых процессов (программы Brain); другое - в изучении состояний сознания личности в обществе. В совокупности работ констатируется многомерность и многоуровневость явлений сознания, идентифицированы такие состояния сознания, как сенсорное, перцептивное, когнитивное, аффективное и др. [Акопов 2019].

В настоящей статье приведены результаты эмпирического исследования цветового и формативного (геометрические фигуры) ассоциативного опосредствования социальных и личностных отношений как разновидности состояний сознания.

Понятие «отношения» входит в качестве неотъемлемой составной части в категориальный состав сознания [Акопов 2010: 136-143]. Следует отметить, что первоначальное многостороннее обоснование отношения как «целостной системы индивидуальных, избирательных, сознательных связей личности с различными сторонами объективной действительности» было дано В.Н. Мясищевым [Мясищев 1995: 16].

В качестве важных характеристик отношения можно выделить модальность (или модус), т.е. конкретный объект отношения (политика, экономика, религия и т.д.), широту-узость, дифференцированность, знак, интенсивность, устойчивость и др.

В последующих изысканиях были определены отличительные особенности отношения как содержательного субъект-объектного явления [Панов 2014] с установкой (динамический аспект отношения), со смыслом (социальный и личностный аспект отношения), а также с оценкой (репрезентативный аспект) [Акопов 2019].

Таким образом, в последовательности объективных определений социальных и иных объектов: оценка (шкальная или ранговая), отношение, установка, смысл отражена уровневая градация осознанности объектов - от полной до частичной представленности в вербальной дискурсивной форме.

В социологических и психологических исследованиях в соответствии с контекстом и задачами можно и полезно проектировать не только вербальные средства измерений субъективных явлений, используя различные «языки» сознания. В нашем случае были привлечены цветовые и фигуративные образы в качестве посредников в диагностике избранных социальных отношений (различные страны мира) и личностных отношений (сам субъект и эмоционально значимые лица его окружения). По аналогии с цветовым тестом отношений (ЦТО) [Бажин, Эткинд 2018; Эткинд 2014] был подготовлен геометрический вариант из 8 фигур: круг, овал, квадрат, спираль, треугольник, ромб, прямоугольник, зигзаг. Согласно инструкции, участники семинара автономно, последовательно работали с двумя тестовыми материалами, представленными в первой серии 8 цветовыми квадратами $4 \times 4$ см из плотной матовой бумаги. Во второй серии тестовый материал состоял из 8 таких же по качеству и размеру квадратов с изображениями геометрических фигур, заполняющих большую часть площади квадрата (от $80 \%$ до 90\%). Участники в первом опыте первой серии ассоциативно подбирали к каждой из 10 предложенных стран только один подходящий для этой страны цвет, отмечая словом в таблице. Далее, во втором опыте они также ассоциативно определяли последовательно цвет для любимого (или которому симпатизируют) реального человека из своего окружения; человека, который не вызывает никаких чувств, затем - негативно воспринимаемого человека и, наконец, для самого себя. В третьем, последнем опыте первой серии участники располагали все 8 цветов в порядке от самого 
приятного, фиксируемого под номером 1, затем, после удаления из поля зрения этого цвета, следующего самого приятного цвета (номер 2) и т.д. - до оставшегося с присвоением ему номера 8. Таким же образом, без перерыва, во второй серии использовались геометрические фигуры.

Обработка протоколов проводилась по группе в целом. Условно определялись три зоны отношений к заданным объектам (страны и люди): позитивная, включающая три первых выбора, нейтральная - два последующих, и три последних - негативная.

В таблице 1 представлены результаты выборов методом последовательных предпочтений одного из 8, затем 7 и т.д. до последнего оставшегося цвета с присвоением соответствующих рангов 1, 2 и т.д. до 8. Первые три цвета (фигуры) (ранги $1,2,3$ ) условно определяют позитивное отношение к объектам, которым ассоциативно присвоен участником любой из этих трех цветов; также определяется условно негативное отношение участника к объектам, которым присвоен любой из трех последних по рангу цветов (фигур) $(6,7,8)$; оставшиеся два цвета (фигуры) (4 и 5) атрибутируют условно нейтральное отношение к объектам.

В данной классификации применен «мягкий» критерий, в отличие от критерия с двумя первыми $(1,2)$ и двумя последними $(7,8)$ рангами, определяющими более узкие полосы позитивного и негативного отношений и более широкую полосу нейтрального (3, 4, 5, 6 ранги) отношения. Мягкость либо жесткость критерия идентификации отношения избирается исследователем в соответствии с поставленными задачами.

Согласно данным табл. 1, в нашей выборке в полосу позитивных выборов попали зеленый, желтый и красный цвета, а из фигур - круг, овал, квадрат, что совпадает с нашими данными, полученными на других выборках. В полосу условно негативных выборов попали коричневый, серый и черный цвета, а из фигур - ромб, треугольник и зигзаг; аналогичные данные несколько отличаются в других выборках.

Данные по цветовым и геометрическим предпочтениям после усреднения по всей группе в долях единицы представлены в табл. 1. Отметим, что в данном исследовании такие характеристики цвета, как цветовой тон, насыщенность и светлота (яркость) стимульного материала были предварительно зафиксированы и являлись неизменными для всех участников; уровень освещенности в аудитории оставался неизменным в процессе проведения работы.

Таблииа 1

\begin{tabular}{|c|c|c|c|c|c|c|c|}
\hline \multirow{2}{*}{ Цвет } & \multicolumn{3}{|c|}{$\begin{array}{c}\text { Предпочтения цвета } \\
\text { по всей выборке }\end{array}$} & \multirow{2}{*}{ Фигура } & \multicolumn{3}{|c|}{$\begin{array}{c}\text { Предпочтения фигуры } \\
\text { по всей выборке }\end{array}$} \\
\hline & + & $\mathbf{0}$ & - & & + & 0 & - \\
\hline Красный & 0,53 & 0,33 & 0,13 & Круг & 0,81 & 0,09 & 0,10 \\
\hline Желтый & 0,63 & 0,47 & 0,00 & Овал & 0,63 & 0,18 & 0,19 \\
\hline Зеленый & 0,93 & 0,07 & 0,00 & Квадрат & 0,54 & 0,28 & 0,18 \\
\hline Синий & 0,33 & 0,40 & 0,27 & Спираль & 0,45 & 0,16 & 0,40 \\
\hline Фиолетовый & 0,33 & 0,47 & 0,20 & Треугольник & 0,19 & 0,27 & 0,54 \\
\hline Коричневый & 0,13 & 0,07 & 0,80 & Ромб & 0,19 & 0,45 & 0,36 \\
\hline Черный & 0,07 & 0,13 & 0,80 & Прямоугольник & 0,19 & 0,54 & 0,27 \\
\hline Серый & 0,13 & 0,13 & 0,73 & Зигзаг & 0,00 & 0,19 & 0,81 \\
\hline
\end{tabular}

На семинаре в качестве объектов личностных отношений были обозна- 
чены: «любимый (симпатичный) человек», «неприятный человек», «ничем не примечательный человек» (все реальные люди из личного окружения) и сам участник семинара («Я») как объект самоотношения. Такой состав объектов отношения обеспечивает возможность проверки искренности респондентов, а также исключения из выборки псевдоучастников, манипуляторов и других девиантных субъектов. Дело в том, что указанные объекты по знаку отношений аналогичны критериальным признакам диагностируемых отношений, заложенным в описанный инструментарий, поэтому явное или неявное нарушение респондентом процедуры действий приводит к очевидным несоответствиям в результатах диагностики личностных отношений, в частности, эквивалентность самоотношения и отношения к любимому человеку и т.д. В нашем случае, согласно данным табл. 2, коэффициенты позитивного отношения к любимому человеку и к себе очень близки по значениям как в цветовой, так и в геометрической атрибуциях; нет противоречия и в значениях других коэффициентов.

Таблица 2

\begin{tabular}{|l|c|c|c|c|c|c|}
\hline & \multicolumn{3}{|c|}{ ЦТО } & \multicolumn{3}{c|}{ ГТО } \\
\cline { 2 - 7 } & + & $\mathbf{0}$ & - & + & $\mathbf{0}$ & - \\
\hline $\begin{array}{l}\text { Любимый (симпатичный } \\
\text { для меня) реальный } \\
\text { человек }\end{array}$ & 1 & 0,00 & 0,00 & 0,90 & 0,00 & 0,10 \\
\hline $\begin{array}{l}\text { Неприятный для меня } \\
\text { реальный человек }\end{array}$ & 0,07 & 0,13 & 0,80 & 0,00 & 0,28 & 0,72 \\
\hline $\begin{array}{l}\text { Человек, который мне } \\
\text { безразличен (реальный } \\
\text { образ) }\end{array}$ & 0,20 & 0,07 & 0,73 & 0,19 & 0,18 & 0,63 \\
\hline \begin{tabular}{l} 
Я (образ себя) \\
\hline
\end{tabular} & 1 & 0,00 & 0,00 & 1 & 0,00 & 0,00 \\
\hline
\end{tabular}

Центральный момент нашего исследования связан с показателями изменения (сдвига) коэффициентов тех или иных отношений при переходе от цветовых к геометрическим посредникам. В связи с тем, что, согласно данным табл. 2, этот сдвиг весьма незначителен, можно прийти к заключению об эквивалентности диагностических возможностей как цветового, так и геометрического опосредствования при выявлении субъективных отношений личности.

Важным моментом любого исследования является его контекст, т.е. установка сознания участников [Яньшин 2001: 102-103], формируемая не только инструкцией, но и процессуальными характеристиками заданной активности. В нашем случае при выполнении первого и второго задания в каждой серии имели место объектные контексты (цветовые атрибуции различных стран и личностных отношений), а в третьем задании проявлялся субъектный контекст (ранжировка цвета согласно индивидуальным предпочтениям участников). Актуализация двух контекстов, т.е. установок сознания, соответствует замыслу исследования, в котором сопоставляются результаты опосредствования социальных и личностных отношений при помощи цветового и геометрического «языков» сознания.

В таблице 3 представлены результаты диагностики ассоциативно-цветового 
и геометрического отношения респондентов к таким большим странам, как Россия, США и Канада. Как видим, в цветовом измерении позитивное отношение наиболее выражено к России - 0,86, затем к Канаде - 0,47 и США 0,40 .

\begin{tabular}{|l|c|c|c|c|c|c|}
\hline \multirow{2}{*}{\multicolumn{1}{|c}{ Страны }} & \multicolumn{3}{c|}{ ЦТО } & \multicolumn{3}{c|}{ Габлица 3 } \\
\cline { 2 - 8 } & + & $\mathbf{0}$ & - & + & $\mathbf{0}$ & - \\
\hline Россия & 0,86 & 0,07 & 0,07 & 0,63 & 0,18 & 0,19 \\
\hline США & 0,40 & 0,40 & 0,20 & 0,27 & 0,10 & 0,63 \\
\hline Канада & 0,47 & 0,40 & 0,13 & 0,45 & 0,18 & 0,37 \\
\hline
\end{tabular}

Соответственно представлены цветоассоциативные оценки нейтрального $(0,40$ у США и Канады) и негативного отношения: Россия - 0,07, США - 0,20, Канада $-0,13$. В ассоциативно-геометрическом измерении соотношение оценок аналогично ассоциативно-цветовому за исключением нейтральных оценок, существенно уменьшившихся по значению для США и Канады с соответствующим увеличением негативных оценок США - 0,63 и Канады - 0, 37 (см. табл. 3).

Таким образом, отношение респондентов к социальным объектам, таким как большие страны, диагностируемое непрямыми ассоциативно опосредствованными измерениями, в целом соответствует социологическим данным, полученным прямыми измерениями. Вместе с тем, в отличие от цветового опосредствования измерений, геометрическое опосредствование в большей степени поляризует оценки за счет «сдвига» нейтральных оценок в сторону некоторого увеличения для страны гражданства респондентов и существенного уменьшения нейтральных оценок для других стран в случае ассоциативно-геометрического опосредствования в диагностике отношений. Различия отчасти можно объяснить спецификой и большей представленностью сенсорного сознания в цветовом ассоциировании в сравнении с актуализацией перцептивного сознания при геометрическом ассоциировании [Артемьева 1980; Петренко 2005].

Подтверждение выявленной тенденции отчасти представлено в табл. 4 и табл. 5. Так, ассоциативно-цветовая позитивная оценка таких стран, как Англия, Германия, Италия и Франция (см. табл. 4) сопоставима с аналогичными для США и Канады (см. табл. 3) при наименьшем значении числового показателя для Германии - 0,33. Вместе с тем интересно отметить, что негативные оценки при цветоассоциативном опосредствовании измерений отношения значительно выше в европейских странах (за исключением Италии) в сравнении с аналогичными в больших странах (см. табл. 3 и 4).

\begin{tabular}{|l|c|c|c|c|c|c|}
\hline \multirow{2}{*}{ Европейские страны } & \multicolumn{3}{|c|}{ ЦТО } & \multicolumn{3}{c|}{ Габлица 4 } \\
\cline { 2 - 7 } & + & $\mathbf{0}$ & - & + & $\mathbf{0}$ & - \\
\hline Англия & 0,40 & 0,20 & 0,40 & 0,36 & 0,10 & 0,54 \\
\hline Германия & 0,33 & 0,33 & 0,33 & 0,45 & 0,36 & 0,18 \\
\hline Италия & 0,40 & 0,47 & 0,13 & 0,37 & 0,18 & 0,45 \\
\hline Франция & 0,46 & 0,27 & 0,27 & 0,45 & 0,19 & 0,36 \\
\hline
\end{tabular}

Ассоциативно-геометрическое опосредствование измерений отношения респондентов к избранным европейским странам по численным значениям 
весьма сходно с ассоциативно-цветовым (см. табл. 4). На наш взгляд, это можно объяснить политическим и финансово-экономическим «весом» этих стран и его отражением в сознании респондентов, т.е. сфокусированность сознания респондентов на политико-экономическом статусе препятствует «тонкой» дифференциации сенсорной и перцептивной (более ассоциативной и менее рецептивной, рациональной) включенности опосредствования.

В иной логике (экономические санкции - Иран, специфическая война Сирия, туризм - Турция) можно сопоставлять численные показатели, представленные в табл. 5.

Таблица 5

\begin{tabular}{|l|c|c|c|c|c|c|}
\hline \multirow{2}{*}{\multicolumn{1}{|c|}{ Страны }} & \multicolumn{3}{|c|}{ ЦТО } & \multicolumn{3}{c|}{ ГТО } \\
\cline { 2 - 7 } & + & $\mathbf{0}$ & - & + & $\mathbf{0}$ & - \\
\hline Иран & 0,27 & 0,27 & 0,46 & 0,27 & 0,28 & 0,45 \\
\hline Сирия & 0,33 & 0,07 & 0,60 & 0,37 & 0,18 & 0,45 \\
\hline Турция & 0,53 & 0,27 & 0,20 & 0,27 & 0,54 & 0,19 \\
\hline
\end{tabular}

С учетом этих факторов активации сенсорно-перцептивного сознания респондентов, более весомых, на наш взгляд, в сравнении с политико-экономическими факторами социологической и психологической оценки больших и европейских стран, можно интерпретировать полученные в опосредствованных измерениях результаты.

Следует отметить, что атрибуция позитивного, нейтрального и негативного отношения к социальным и личностным объектам респондентов (участников семинара) в данном исследовании основана на ранжированных субъективно-положительных предпочтениях цветовых и геометрических посредников отношения. Возможны и иные схемы выявления предпочтений: также по унитарному критерию, но с позиций субъективного отвержения - самый непривлекательный цвет (фигура) и далее до последнего стимула; по бинарному критерию - самый приятный и самый неприятный из всех стимулов и далее из остающихся до двух дифференцированных последних. Возможно, что в социологически ориентированных измерениях очевидными психологическими различиями в субъективной репрезентации опосредствованного отношения можно пренебречь, а в психологически ориентированных измерениях появляется перспектива исследований когнитивного сознания в аспектах дифференциации и интеграции сенсорного и перцептивного состояний сознания [Чуприкова 2011].

Таким образом, по результатам нашего исследования можно сделать следующие выводы.

1. Наряду с процедурами прямой оценки субъективного отношения респондентов к социальным и личностно-значимым объектам, возможно в качестве дополнительных или уточняющих использовать процедуры опосредствованной оценки, используя в качестве посредников цвет, геометрические формы или другие стимулы, соответствующие тем или иным видам сознания (сенсорное, перцептивное, аффективное и т.д.), согласно современной методологии многомерности сознания человека и типологически определенным задачам исследования.

2. Включение личностно значимых объектов в объектное поле социологических и психологических исследований, а также процедур опосредствования 
измерений позволяет повысить содержательное качество исследования, его достоверность в части устранения явлений социальной желательности, оппозиционности, манипулятивности и других помех во взаимодействии исследователя и респондента.

3. Факторы того или иного статуса социальных объектов, в данном случае финансово-политического, экономического, правового и др., а также событийно-ситуативного в случае их дифференциации в качестве переменных позволяют расширить анализ и интерпретацию дифференцированных по видам сознания показателей субъективного отношения респондентов к этим объектам.

Публикуется при поддержке Школы молодого этнополитолога в Республике Башкортостан (грант Фонда президентских грантов 19-2-022447).

\section{Список литературы}

Акопов Г.В. 2010. Психология сознания. Вопросы методологии, теории и прикладных исследований. М.: Изд-во Института психологии РАН. 270 с.

Акопов Г.В. 2016. Социальное управление: проблема бесконфликтных переходов от традиционного к обществу модерна. - Социальная психология религиозного (конфессионального), этно-национального, правового и регулятивно-управленческого сознания в современной России (отв. ред. Г.В. Акопов, Е.В. Бакшутова, Т.К. Рулина). Самара: Порто-принт. С. 182-190.

Акопов Г.В. 2019. Категория сознания в современной психологии: избранные работы, опубликованные в 2003-2018 гг. Самара: Порто-принт. 278 с.

Артемьева Е.Ю. 1980. Психология субъективной семантики. М.: Изд-во МГУ. $128 \mathrm{c}$.

Бажин Е.Ф., Эткинд А.М. 2018. Изучение эмоционального значения цвета. Психологические методы исследования личности. СПб: Иматон.

Мясищев В.Н. 1995. Психология отношений: избранные психологические труды. М.: Изд-во Института практической психологии; Воронеж: НПО МОД ЭК. 356 с.

Панов В.И. 2014. Экопсихология: Парадигмальный поиск. М.; СПб: Нестористория. $296 \mathrm{c.}$

Петренко В.Ф. 2005. Основы психосемантики. 2-е изд., доп. СПб: Питер. 479 с.

Петренко В.Ф. 2013. Многомерное сознание: психосемантическая парадигма. 2-е изд., доп. М.: Эксмо. 443 с.

Чуприкова Н.И. 2011. Всеобщий универсальный дифференционно-интеграционный закон развития как основа междисциплинарной парадигмальной теории. - Дифференционно-интеграционная теория (сост. Н.И. Чуприкова, А.Д. Кошелев). М.: Языки славянских культур. С. 11-47.

Эткинд А.М. 2014. Цветовой тест отношений. - Общая психодиагностика (под ред. А.А. Бодалева, В.В. Столина). СПб: Речь. 440 с.

Яньшин П.В. 2001. Введение в психосемантику ивета: учебное пособие. Самара: Изд-во СамГПУ. 189 с. 
AKOPOV Garnik Vladimirovich, Dr.Sci. (Psych.), Professor; Head of the Chair of General and Social Psychology, Faculty of Psychology, Samara State University of Social Sciences and Education (65/67 M. Gor'kogo St, Samara, Russia, 443099; kaf.soc.ps@sgspu.ru); Honored Scientist of the Russian Federation

AKOPYAN Liubov' Surenovna, Dr.Sci. (Psych.), Associate Professor, Professor of the Chair of Pedagogy and Psychology, Samara State University of Social Sciences and Education (65/67 M. Gor'kogo St, Samara, Russia, 443099; akolubov@mail.ru) BELOUS Anna Vyacheslavovna, postgraduate student at the Chair of General and Social Psychology, Faculty of Psychology, Samara State University of Social Sciences and Education (65/67 M. Gor'kogo St, Samara, Russia, 443099)

\title{
ASSOCIATIVE CONSCIOUSNESS IN COLOR AND GEOMETRIC PROJECTIONS: SOCIOLOGICAL AND PSYCHOLOGICAL ASPECTS OF THE DIAGNOSIS OF RELATIONSHIPS
}

\begin{abstract}
The material examines the method of researching respondents' assessments of social phenomena, which provides for a departure from the direct verbal designation of a person's relationship to an object or process. The presence of an intermediate sign, with which the respondent associates his attitude to the phenomenon under study, helps to reveal the respondent's real subconscious position about the phenomena that in his mind is linked to the official socially approved position. The approach helps to improve the quality of the primary material collected during the survey, because it can significantly reduce the number of answers that respondents give not in accordance with the existing individual position, but by linking them to the expectations of the interviewer, considering the questions of the questionnaire as a test of loyalty. Keywords: sociological survey methodology, psychological testing, diagnostics of personality relationships, color-associative assessments, associative-geometric assessments, object contexts, subjective contexts
\end{abstract}

\section{УДК 24-17}

АБАЕВА Любовь Лубсановна - доктор исторических наук, профессор; главный научный сотрудник отдела философии, культурологии и религиоведения Института монголоведения, буддологии и тибетологии СО РАН (670047, Россия, г. Улан-Удэ, ул. Сахьяновой, 6; luba-abaеva@таil.ru)

\section{СТРАТЕГИИ И ТЕНДЕНЦИИ РАЗВИТИЯ БУДДИЙСКОЙ КОНФЕССИИ В МОНО- И ПОЛИЭТНИЧЕСКИХ СОЦИУМАХ МОНГОЛЬСКОГО МИРА}

\begin{abstract}
Аннотация. В статье анализируются стратегии и тенденции развития буддийской конфессии в целом и буддийских теорий и практик в частности в моноэтнических (Монголия) и полиэтнических (Внутренняя Монголия КНР, республики Бурятия, Калмыкия и Тыва РФ) сообществах монгольского мира. Постулируется, что различные части пространства монголосферы, имеющие общие историко-генетические корни, в контексте различных социальных, политических и экономических реалий конкретных исторических событий дифференцировано выбирали стратегию и тактику по отношению к буддизму.
\end{abstract}

Ключевые слова: буддизм, монгольские народы, моноэтническое и полиэтническое пространство, стратегии, тенденции развития

конца XIII в. в Восточной и Центральной Азии и на Ближнем Востоке фиксируется небывалый размах культурного возрождения, выразившийся не 